\title{
Randomised study demonstrates sustained benefits of a pre- school intervention designed to improve nutrition and physical activity practices
}

\author{
Diewerke de Zwarte \\ Technological University Dublin, Diewerkedezwarte@gmail.com \\ John Kearney \\ Technological University Dublin, john.kearney@tudublin.ie \\ Clare A. Corish \\ University College Dublin
}

See next page for additional authors

Follow this and additional works at: https://arrow.tudublin.ie/scschbioart

Part of the Community Health Commons, Community Health and Preventive Medicine Commons, Maternal and Child Health Commons, and the Public Health Education and Promotion Commons

\section{Recommended Citation}

de Zwarte D, Kearney J, Corish CA, Glennon C, Maher L, Johnston Molloy C. Randomised study demonstrates sustained benefits of a pre-school intervention designed to improve nutrition and physical activity practices. J Public Health (Oxf). 2019 Dec 20;41(4):798-806. doi: 10.1093/pubmed/fdy173. PMID: 30281073.

This Article is brought to you for free and open access by the School of Biological Sciences at ARROW@TU Dublin. It has been accepted for inclusion in Articles by an authorized administrator of ARROW@TU Dublin. For more information, please contact arrow.admin@tudublin.ie, aisling.coyne@tudublin.ie,gerard.connolly@tudublin.ie. Funder: Health Service Executive, Ireland

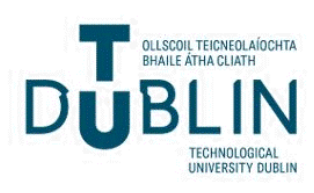




\section{Authors}

Diewerke de Zwarte, John Kearney, Clare A. Corish, Corina Glennon, Lorraine Maher, and Charlotte Johnston Molloy 


\title{
Randomised study demonstrates sustained benefits of a pre-school intervention designed to improve nutrition and physical activity practices
}

\section{Diewerke de Zwarte ${ }^{1}$, John Kearney ${ }^{1}$, Clare A. Corish ${ }^{2}$, Corina Glennon ${ }^{3}$, Lorraine Maher ${ }^{3}$, Charlotte Johnston Molloy ${ }^{3}$}

${ }^{1}$ School of Biological Sciences, Dublin Institute of Technology, Dublin 8, Republic of Ireland

${ }^{2}$ School of Public Health, Physiotherapy and Sports Science, University College Dublin, Belfield, Dublin 4, Ireland

${ }^{3}$ Community Nutrition and Dietetic Service, Health Service Executive Dublin Mid-Leinster, Primary Care Unit, St. Loman's Hospital Campus, Co. Westmeath, Republic of Ireland Address correspondence to Diewerke de Zwarte, 51 Fort Ostman, Old County Road, Crumlin, Dublin 12, Ireland. E-mail: Diewerkedezwarte@gmail.com

\begin{abstract}
Background Health-promoting programmes must demonstrate sustained efficacy in order to make a true impact on public health. This study aimed to determine the effect of the Healthy Incentive for Pre-schools project on health-promoting practices in full-day-care pre-schools 18 months after a training intervention.

Methods Thirty-seven pre-schools completed the initial study and were included in this follow-up study. The intervention consisted of one training session with either the pre-school 'manager-only' or 'manager and staff' using a specifically developed needs-based training resource pack comprised of written educational material and a validated health-promoting practice evaluation tool. Direct observation data of health-promoting practices were collected and allocated a score using the evaluation tool by a research dietitian at three time points; pre-intervention, between 6 and 9 months post-intervention and at 18-month follow-up. An award system was used to incentivise pre-schools to improve their scores.

Results Health-promoting practice scores improved significantly $(P<0.001)$ from the $6-9$ month post-intervention to the 18-month follow-up evaluation. No significant differences were observed between 'manager-only' and 'manager and staff' trained pre-schools.

Conclusions The introduction of a pre-school evaluation tool supported by a training resource was successfully used to incentivise pre-schools to sustain and improve health-promoting practices 18 months after intervention training.
\end{abstract}

Keywords health, incentive, nutrition, physical activity, pre-school, sustainable

\section{Introduction}

While it is well recognised that nutrition and physical activity in early life have consequences for adult health, ${ }^{1-3}$ it has been shown that nutritional intakes and behaviours in young children are suboptimal ${ }^{4-8}$ and that many children do not meet desired physical activity levels. ${ }^{9,10}$ Evidence-based interventions to improve health-related behaviours in young children are needed, ${ }^{11,12}$ and the pre-school setting has been highlighted as a promising area for the introduction of these interventions. $^{11,13-15}$ In response to the inadequate healthpromoting practice noted, ${ }^{16-19}$ programmes are emerging which aim to improve nutrition and physical activity standards in the pre-school environment. ${ }^{12,20-26}$
The Healthy Incentive for Pre-schools (HIP) Project ${ }^{21}$ is the first randomised intervention study into nutrition and physical activity practice to take place in the Irish full-daycare pre-school setting. Published results of the project to date demonstrated significant directly observed improvements in nutrition and health related practices when

Diewerke de Zwarte, Dietitian

John Kearney, Professor in Nutrition and Epidemiology

Clare A. Corish, Associate Professor in Nutrition and Dietetics

Corina Glennon, Community Dietitian Manager

Lorraine Maher, Dietitian

Charlotte Johnston Molloy, Senior Community Dietitian 
measured 6-9 months post-intervention training, ${ }^{27}$ with no difference found between training groups.

If such interventions are to be funded by governmental agencies, then programmes must prove to be cost-efficient and demonstrate sustainable efficacy. ${ }^{28,29}$ Therefore, the sustainability of the HIP project needed to be investigated. ${ }^{30}$ Here, we report the results of an 18-month follow-up study of the HIP project which aimed to ascertain whether the significant improvements in practice observed 6-9 months post-intervention were sustained in the longer term at an 18-month follow-up.

\section{Methods}

\section{Study design}

In summary, the HIP project is a randomised, parallel-group study (with balanced randomisation [1:1] using a random number table) that took place in four midland counties of Ireland from 2008 to 2013. The hypothesis, design and 6-9 month results of the HIP project have been previously published. ${ }^{27}$ This study followed-up the full-day-care preschools originally enrolled in the HIP project.

The study was conducted according to the guidelines laid down in the Declaration of Helsinki and was approved by the Research Ethics Committee of the Health Service Executive Dublin Mid-Leinster, Ireland and the Ethics Committee of the Dublin Institute of Technology, Ireland. Written informed consent was obtained prior to data collection from all pre-school managers participating in the project.

\section{Participating centre recruitment}

Full-day-care pre-schools were selected from a convenience sample of pre-schools registered with the Irish Health Service Executive (HSE). All pre-schools in Ireland must be registered with the HSE in order to operate as an 'Early Years Service'. Hence, results from this study are expected to be generalisable to other registered Irish Pre-schools. Pre-schools included in the study included both publicly and privately funded pre-schools and were situated in towns, villages and the countryside.

Full-day-care was defined as 'a pre-school service offering a structured day-care service for pre-school children for more than $5 \mathrm{~h} / \mathrm{d}$ '. Exclusion criteria included pre-schools deemed ineligible by the Irish Health Service Executive Preschool Inspection Team due to inadequate standards in predefined areas of inspection, pre-schools that had not been inspected by the Pre-school Inspection Team in the previous 12 months, and pre-schools providing less than $5 \mathrm{~h} / \mathrm{d}$ of care. Pre-schools were randomised using a random-number table by the research dietitian, and allocated into two parallel intervention groups. One group received 'manager-only' training $(n=30)$ and the other group received 'manager and staff' training $(n=31)$.

Pre-schools were included in this follow-up study if they had completed the pre-intervention phase, the intervention phase and the initial post-intervention observation visit of the HIP project. Forty-two pre-schools were invited to participate in the 18-month follow-up study. In the 'manageronly' training group, one pre-school was excluded due to a change in service provision. In the 'manager and staff' training group, four pre-schools were excluded due to closure of service $(n=1)$, inadequate staff levels $(n=1)$, maternity leave $(n=1)$ and lack of interest $(n=1)$. Thirty-seven preschools took part in the 18-month follow-up observation visits. Figure 1 outlines the timeline of the HIP project phases.

\section{HIP project intervention tools}

The HIP project centres on the use of two specifically developed tools: the 'Pre-school Health Promotion Activity Scored Evaluation Form' and an accompanying explanatory guide, the 'Pre-school Nutrition and Health Education Resource pack'.

The 'Pre-school Health Promotion Activity Scored Evaluation Form, ${ }^{21}$ was developed to enable the scoring of pre-school practices. A number of phases were undertaken to determine the validity of this form. These are previously described by Johnston Molloy et al. ${ }^{21,27,31}$ The form consists of four sections: Environment, Food service, Meals, and Snacks. Within each section, six criteria are specified (Fig. 2). For each criterion, a pre-school can be scored at three grades; 'not following minimal practice' (zero points), 'following minimal practice' (one point) or 'best practice' (three points). The requirements for meeting each grade of these criteria are further described in the 'Pre-school Nutrition and Health Education Resource pack'. Each of the Environment, Food service, Meals, and Snacks sections is scored out of 18, resulting in a maximum overall score of 72. For the use of the award classification system, a classification of 'Participation' was awarded at a score of $0-19$, 'Bronze' at 20-39, 'Silver' at 40-54, 'Gold' at 55-64 and 'Platinum' at 65-72.

The 'Pre-school Nutrition and Health Education Resource pack' was specifically developed from needs identified in the pre-intervention study and consists of two books: the 'Best Practice Guide' (which outlines the standards of practice required for the three scoring grades of each 


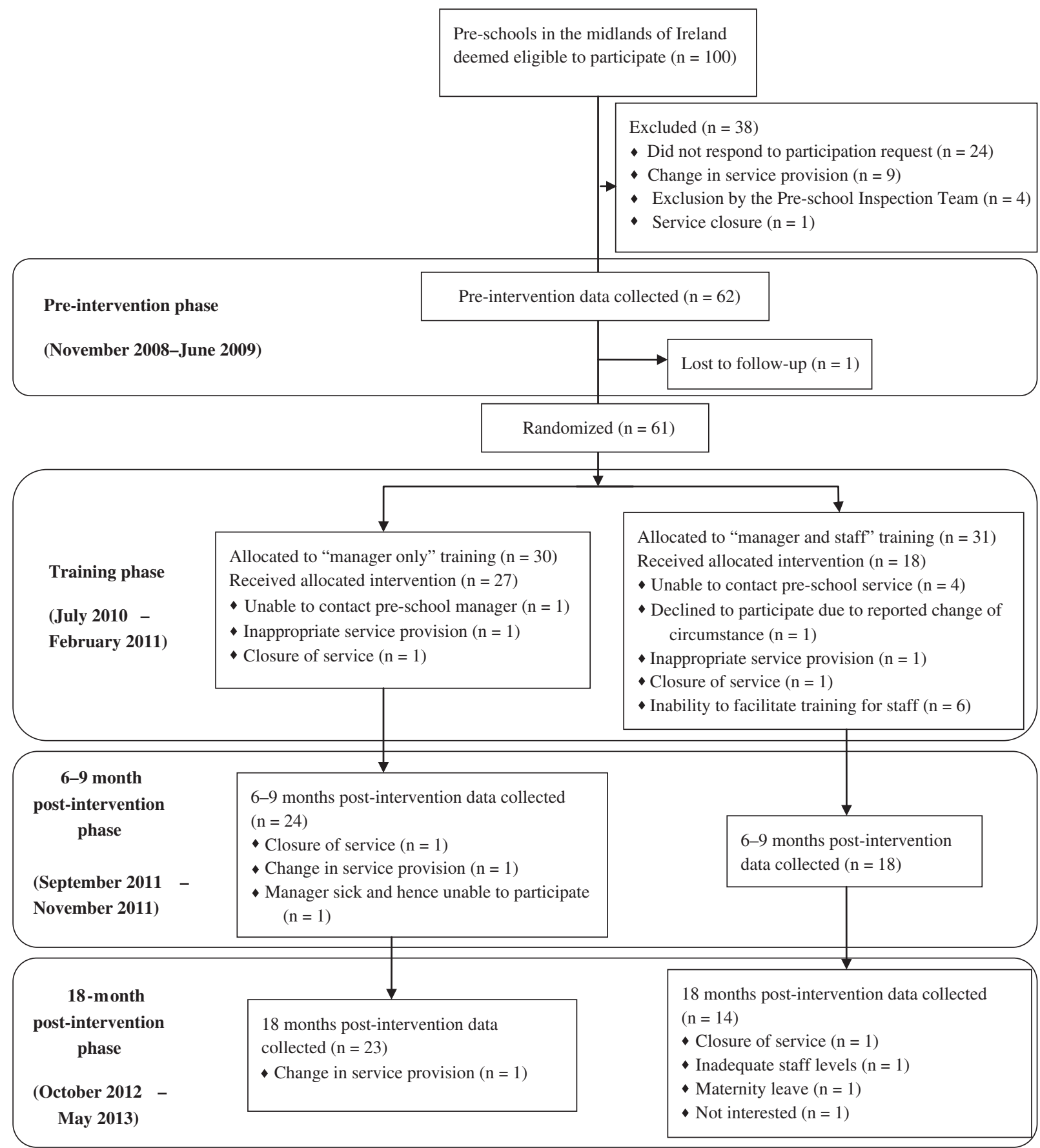

Fig. 1 Timeline of HIP project phases.

criterion on the scored evaluation) and the 'Hints and Tips' pack (which provides practical ideas to help services meet these standards).

A number of other tools used were also specifically developed for the HIP project. The Pre-school Characteristic Collection Form ${ }^{21}$ was used to compile the pre-school characteristics, and the 'Pre-school Detailed Assessment Tool $^{21}$ was used by the research dietitian to record and provide detail of the nutrition and health-related practices observed during the pre-school visits. A 'Pre-school Photographic Food Atlas ${ }^{32}$ was produced to allow for quantification of portion sizes provided in the pre-schools. 


\begin{tabular}{|l|l|}
\hline Sections & Criteria \\
\hline \multirow{5}{*}{ Environment } & Whole pre-school health policy \\
\cline { 2 - 3 } & Education-related activities \\
\cline { 2 - 3 } & Planned physical activity \\
\cline { 2 - 3 } & Outside playtime \\
\cline { 2 - 3 } & Evidence of food use as reward/treat \\
\hline \multirow{5}{*}{ Meod Service } & Appropriate number of meals and snacks \\
\cline { 2 - 3 } & Staff sitting with children at food times \\
\cline { 2 - 3 } & Staff eating same food as children at food times \\
\cline { 2 - 3 } & Practice of 'family-style food service' \\
\cline { 2 - 3 } & Adequate allocation of time for food times \\
\cline { 2 - 3 } & self-feeding \\
\hline \multirow{5}{*}{ Snacks } & Appropriate serving of protein at main meal \\
\cline { 2 - 3 } & Appropriate serving of starch at main meal \\
\cline { 2 - 3 } & Appropriate serving of dairy at main meal \\
\cline { 2 - 3 } & Appropriate serving of vegetables at main meal \\
\cline { 2 - 3 } & Meals offered in self-service style \\
\cline { 2 - 3 } & Fe-rich food provision at main meal \\
\hline & Fruit at least once other than main meal \\
\cline { 2 - 3 } & Foods offered from top shelf of the Food Pyramid \\
\cline { 2 - 3 } & Dairy food at least once other than main meal \\
\cline { 2 - 3 } & Tap water and milk only with snacks \\
\cline { 2 - 3 } & Tap water, milk or appropriately diluted juice with meals \\
\cline { 2 - 3 } & Tap water or milk offered between meals and snacks \\
\hline
\end{tabular}

Fig. 2 Pre-school Health Promotion Activity Scored Evaluation Form sections and criteria.

\section{Delivery of HIP project intervention training}

'Manager-only' trained intervention

Following pre-intervention Pre-school Health Promotion Activity Scored Evaluation Form score data collection, a one-hour face-to-face training session with each pre-school manager in this group was provided by the research dietitian. An individualised feedback form based on the preintervention observation scores was provided to each manager and discussed. The Pre-school Nutrition and Health Education Resource pack was introduced to the manager and the best practice standards for the criteria on the Scored Evaluation Form were highlighted. One copy of the Resource pack per staff member was given to the manager for distribution. Twenty-three pre-schools that received 'manager-only' training participated in the follow-up data collection.

\section{'Manager and staff' trained intervention}

Manager training in this group was equivalent to that provided for the 'manager only' trained group. In addition to this training, a 1.5-h on-site training session was provided by the research dietitian for the staff. The session included presentations on the topics covered by the Scored Evaluation Form and the use of the 'Pre-school Nutrition and Health Education Resource pack'. Presentations were delivered on a table-top A1 presentation device. The topics were followed by group work exercises. Fourteen pre-schools that received 'manager and staff' training participated in the follow-up data collection.

\section{Post-intervention follow-up phase contact}

Following the second observation visit, conducted between 6 and 9 months after intervention training, pre-schools were sent a written report of their practice standard. Pre-schools were sent seasonal newsletters ( 3 per year) to update them on the project's progress and to provide practical tips on how to achieve/maintain best practice. The research dietitian was also available by telephone to answer queries from preschools when necessary.

\section{Outcome measurements}

Data from pre-intervention and at 6-9 month postintervention observation visits were collected by a single research dietitian. Data at the 18-month follow-up visits were collected by a second research dietitian. This dietitian was trained and observed by the primary research dietitian to ensure the completion of the 'Pre-school Health Promotion Activity Scored Evaluation Form' achieved comparable results. Inter-rater reliability was not statistically assessed.

The observation visits were arranged at least two weeks in advance. Each pre-school was contacted by telephone to arrange a suitable date and time to visit. Visits were held on each day of the working-week, and data were collected at each pre-school for a full day at each data collection time point. Pre-school visits started $\sim 45 \mathrm{~min}$ to an hour before the time of the first food service. Pre-school characteristics were recorded on the 'Pre-school Characteristic Collection Form'. The 'Pre-school Detailed Assessment Tool' was then used to record observations of each meal and snack time in the pre-school day, portion size using the specifically designed photographic food atlas, ${ }^{32}$ description of food served, meal time experience, staff and child interaction and room environment, physical activity participation and outdoor physical activity time. These observations were then compared to the project's best practice criterion standards on the 'Pre-school Health Promotion Activity Scored Evaluation Form'. Scores were summed and classified into five categories: 'participation', 'bronze', 'silver', 'gold' and 'platinum' categories.

\section{Data analyses}

For this study, data were analysed for changes in practice from the 6-9 month post-intervention visits to 18 -month follow-up visits using the statistical software package IBM SPSS Statistics Version 22. The 37 pre-schools that 
participated in the 18-month follow-up visits were included in the analysis. Normality of distribution was assessed using the Shapiro-Wilk test. Due to the skewed distribution of the data, the Wilcoxon Signed Rank test was used to analyse the characteristics of the pre-schools from the 6-9 month postintervention phase to the 18-month follow-up phase. Differences between intervention groups at the 18-month visits were analysed using a Mann-Whitney $U$ test. Parametric statistical tests (Paired t-tests) were used to analyse evaluation scores as both 6-9 month post-intervention and 18-month follow-up scores were normally distributed.

Eta-squared was calculated for significant parametric results to identify effect size, which was classified as follows: $>0.01$ (small effect size), >0.06 (moderate effect size) and $>0.14$ (large effect size). A p-value less than 0.05 was used as the cut-off for statistical significance.

\section{Results}

\section{Characteristics of the pre-schools}

A total of 37 pre-schools participated in the follow-up data collection phase, of which 23 were 'manager only' trained and 14 were 'manager and staff' trained. No significant differences were found in pre-school characteristics between these groups in the follow-up data. A mix of community $(n=23)$ and private $(n=14)$ pre-schools was represented in the study group. No significant changes occurred in preschool characteristics from the 6-9 month post-intervention to 18 -month follow-up visits (Table 1).

\section{Changes in evaluation scores from 6 to 9 months to 18-months post-intervention}

The Pre-school Health Promotion Activity Scored Evaluation Form demonstrated a $21 \%$ overall improvement in the scores attained from the 6-9 month to 18 -month follow-up visits $(P<0.001)$ with a large effect size (Etasquared $>0.14)$. The average improvement in scores was 7.2 (95\% CI: 4.3-10.1). This resulted in an increase in the average score from 34.3 (SD 11.56), 'Bronze' award classification, to 41.5 (SD 11.71), 'Silver' award classification.

\section{'Manager trained' versus 'manager and staff trained'}

Similar Pre-school Health Promotion Activity Scored Evaluation Form scores were observed in both the 'manager-only' trained group [mean score of 41.5 (IQR 33-48)], and the 'manager and staff' trained group [mean score of 42 (IQR 32-51)] at the 18-month follow-up visits $(P=0.769)$.

\section{Participation of pre-schools in follow-up study}

Five pre-schools that had participated in the 6-9 month post-intervention phase of the study did not go on to participate in the 18-month follow-up phase. Those included in the 18-month follow-up study had similar pre-school characteristics to those who did not participate. However, although not significant, the median score attained by pre-schools at the 6-9 month follow-up was demonstrated to be higher in those pre-schools who continued to the 18 month follow-on phase than for those that did not continue with the project.

\section{Discussion}

\section{Main findings of this study}

The results of this study provide valuable insight into the ability of pre-schools to sustain the HIP project standards, and highlight the effect of two levels of intervention on preschool practices. This study found that pre-schools in the HIP project were able to maintain and improve their HIP project practice standards from 6-9 month postintervention to 18-month follow-up, despite minimal postintervention follow-up contact and support. No difference in intervention effects were observed between 'manageronly' trained and 'manager and staff' trained pre-schools.

\section{What is already known on this topic?}

It is recognised that sustained effects of public health interventions are necessary to make a significant positive impact on public health, ${ }^{33}$ as well as to ensure that valuable funding is spent appropriately. ${ }^{28}$ Overall standards of practice in this study, as demonstrated by the Pre-school Health Promotion Activity Scored Evaluation Form scores, improved significantly by $21 \%$ from the $6-9$ months post-intervention visits to the 18-month follow-up visits. This highlights that preschools involved in the HIP project were able to sustain and, importantly, continue to improve the standards set by the HIP project 18 months after the original training took place. This finding is important, particularly when sustainability of intervention effects in the early childcare sector is recognised as challenging ${ }^{34}$ due to high staff turnover ${ }^{35}$ and limited funding. ${ }^{36}$

It is possible that the use of an award, or incentive scheme, in this intervention may have helped to sustain improved practice. The use of such an award system is often referred to as a quality rating and improvement system (QRIS) and has shown the potential to improve practice in childcare settings, ${ }^{25,37,38}$ especially where it may provide a pre-school with a competitive advantage. ${ }^{38}$ Ireland's preschool sector consists of both private and community 
Table 1 Post-intervention and follow-up characteristics

\begin{tabular}{|c|c|c|c|c|c|c|c|c|c|}
\hline & \multicolumn{4}{|c|}{ Post-intervention phase $(\mathrm{n}=37)$} & \multicolumn{4}{|c|}{ Follow-up phase $(\mathrm{n}=37)$} & \multirow[b]{2}{*}{ P value ${ }^{a}$} \\
\hline & $n$ & $\%$ & Median & $I Q R$ & $n$ & $\%$ & Median & $I Q R$ & \\
\hline Total no. of staff & 37 & 100 & 9 & $6-16$ & 37 & 100 & 8 & $6-17$ & 0.279 \\
\hline No. of full-time staff & 37 & 100 & 5 & $3-8$ & 37 & 100 & 5 & $3-8$ & 0.224 \\
\hline No. of part-time staff & 37 & 100 & 3 & $2-8$ & 37 & 100 & 3 & $2-8$ & $0.048^{*}$ \\
\hline Total no. of children attending service & 37 & 100 & 50 & $35-67$ & 37 & 100 & 55 & $35-83$ & 0.218 \\
\hline No. of FDC children & 37 & 100 & 19 & $12-32$ & 37 & 100 & 18 & $12-29$ & 0.071 \\
\hline Minimum age a child may enter pre-school service (months) & 37 & 100 & 6 & $3-6$ & 36 & 97 & 6 & $4-9$ & $0.035^{*}$ \\
\hline Actual age of entry (months) & 35 & 95 & 6 & $6-9$ & 36 & 97 & 7.5 & $6-12$ & 0.063 \\
\hline No. of FDC children aged $<12$ months & 30 & 81 & 1 & $0-2$ & 37 & 100 & 1 & $0-2$ & 0.845 \\
\hline No. of FDC children aged $13-24$ months & 36 & 97 & 4 & $2-5.5$ & 37 & 100 & 3 & $1-6$ & 0.189 \\
\hline No. of FDC children aged $25-36$ months & 37 & 100 & 5 & $2-6$ & 37 & 100 & 6 & $2-9$ & 0.063 \\
\hline No. of FDC children aged $>36$ months & 36 & 97 & 8 & $4.5-13$ & 37 & 100 & 6 & $4-11$ & 0.331 \\
\hline Weekly cost of childcare $(€)$ for FDC children aged $<12$ months & 35 & 95 & 150 & $140-165$ & 34 & 92 & 150 & $145-165$ & 0.529 \\
\hline Weekly cost of childcare (€) for FDC children aged $13-24$ months & 37 & 100 & 150 & $140-165$ & 36 & 97 & 150 & $140-165$ & 0.972 \\
\hline Weekly cost of childcare $(€)$ for FDC children aged 25-36 months & 37 & 100 & 150 & $140-165$ & 37 & 100 & 150 & $140-165$ & 0.529 \\
\hline Weekly cost of childcare $(€)$ for FDC children aged $>36$ months & 37 & 100 & 150 & $140-165$ & 37 & 100 & 150 & $140-165$ & 0.972 \\
\hline Cost of food provision ( $€$ ) per week & 36 & 97 & 200 & $125-250$ & 36 & 97 & 175 & $122-300$ & 0.812 \\
\hline
\end{tabular}

FDC, full day care; IQR, interquartile range; $n$, number of pre-schools; \%, percentage; No, number; $€$, Euro.

${ }^{a}$ Wilcoxon Signed-Rank Test.

${ }^{\star} P<0.05,{ }^{*} * P<0.01,{ }^{* * *} P<0.001$.

funded pre-schools and parents are free to choose between available child-care services. A high HIP award classification may afford participating pre-schools a competitive advantage, creating a further financial incentive for privately funded pre-schools. While not formally studied in this present study due to the smaller number of pre-schools remaining in the study for this follow-up phase, differences between publicly and privately funded pre-schools should be explored if the study was to be repeated. Adequate funding for continued quality improvements remains an important determinant for sustainability of QRIS intervention effects, ${ }^{39,40}$ and for other forms of health-promoting programmes in the school setting. ${ }^{34,41-43}$

The previously published post-intervention data from the HIP project showed no significant difference between 'manager-only' and 'manager and staff' trained intervention groups. ${ }^{27}$ This observation continued in the present study, with no difference found between the two intervention levels at follow-up. This is a positive finding, highlighting that a lower resource requiring intervention such as 'manager-only' training shows similar effects as a higher resource requiring 'manager and staff' training. It is recognised that leaders are often change-makers and in the Early Years sector good leadership is known to affect quality of practice. ${ }^{44,45}$ Thus, the positive effect of leadership on the change process may help to explain the findings of the present study.

However, along with the important role of leadership, the quality of the training material developed for this project may also help explain the improvements observed in the follow-up phase for both intervention groups. The training materials act as a reference guide for best practice criteria and provide practical information on how to implement and achieve the best practice standards. The availability of high quality resources in the HIP project, along with the observation visits and feedback, may possibly negate the need for expensive face-to-face manager/staff training. The dissemination of educational materials ${ }^{46}$ and audit/feedback loops ${ }^{47}$ have demonstrated improvements in professional practice in other areas. Whether the HIP training materials and observation feedback alone are sufficient without manager training and buy-in has yet to be determined.

\section{Limitations of this study}

Some potential limitations of this study must be acknowledged. The sample size of pre-schools is small and must be considered when extrapolating the study results in a wider context. Nonetheless, both pre-schools from private and community sectors are represented and the nutrition and 
physical activity practices observed in the pre-intervention stage of the study are similar to those observed in other studies in this area. ${ }^{6,31,35}$ Thus, learning from the intervention implemented in the present study could be applied to other full-day-care pre-schools.

Although use of a second observer in the follow-up study may be seen as a study limitation, having multiple observers may help to validate results. ${ }^{48}$ Data collection for all phases was through direct observation, which is considered the gold standard for estimating food intake ${ }^{49}$ and evaluating the sustainability of an intervention. ${ }^{28}$ Inter-observer reliability in nutrition studies is often $\operatorname{good}^{50,51}$ and since both training and supervision of the researcher engaged in the follow-up study was performed by the original researcher, the data collected may be considered reliable.

Arranging a date in advance with pre-schools for the follow-up observation day may have allowed pre-schools to prepare for the researcher visit, and thus alter their usual practices. As pre-schools were aware of the standards expected for the assessment of practice, this is a limitation of both the present study and any other intervention involving organised inspections. However, children require regular and constant exposure in order for behaviour to become engrained $^{52}$ and, thus, attempts to change behaviour solely for the observation day are likely to be noticed. Furthermore, the purpose of the assessment visits in the HIP project was to support improvements in practice rather than solely inspect the pre-schools. This created a collaborative relationship between the project coordinators and preschool management which is likely to have reduced the effect of this potential limitation.

\section{What this study adds}

The present study has demonstrated that low resource training of pre-school managers alone, using a school resource pack and evaluation tool, in tandem with a motivational award classification system, and low resource follow-up support led to sustained pre-school nutrition and physical activity health-promoting practices 18 months after intervention training. This is an important finding, especially when sustainability in the childcare setting is known as challenging, and funding in this sector is limited.

Funding for health promotion in pre-schools should be directed to programmes with proven and sustainable results. Empowering and supporting pre-schools through this improvement process using evidence-based training and high-quality validated resources is vital to ensure that costeffective, beneficial effects on public health are achieved.

\section{Acknowledgements}

The authors would like to acknowledge the pre-school services involved in this project for their dedication and time.

\section{Authors' contributions}

The authors Charlotte Johnston Molloy (CJM), John Kearney (JK), Nóirín Hayes (NH), Corina Glennon (CG) and Clare Corish (CC) designed the original study. Lorraine Maher $(\mathrm{MH})$ carried out the new fieldwork under direction from CJM Diewerke de Zwarte (DDZ), under supervision of CJM and JK, was involved in the interpretation of the findings. DDZ wrote the initial draft of the manuscript under the supervision of CJM, JK and CC. All authors critically reviewed the manuscript, contributed to, and agreed upon, the final version to be submitted for publication consideration.

\section{Funding}

This work was supported by the Health Service Executive, Ireland. The original study was supported by safefood.

\section{References}

1 Langley-Evans SC. Nutrition in early life and the programming of adult disease: a review. J Hum Nutr Diet 2015;28(Suppl 1):1-14.

2 Craigie AM, Lake AA, Kelly SA et al. Tracking of obesity-related behaviours from childhood to adulthood: a systematic review. Maturitas 2011;70(3):266-84.

3 Guo SS, Wu W, Chumlea WC et al. Predicting overweight and obesity in adulthood from body mass index values in childhood and adolescence. Am J Clin Nutr 2002;76(3):653-8.

4 Shim JE, Yoon JH, Kim K et al. Association between picky eating behaviors and growth in preschool children. J Nutr Health 2013;46 (5):418-26.

5 Hazell TJ, Pham TT, Jean-Philippe S et al. Vitamin D status is associated with bone mineral density and bone mineral content in preschool-aged children. J Clin Densitom 2015;18(1):60-7.

6 Walton J; National Pre-School Nutrition Survey Summary Report on: Food and Nutrient Intakes, Physical Measurements and Barriers to Healthy Eating; iuna.net; Irish Universities Nutrition Alliance; 2012

7 Scientific Advisory Committee on Nutrition; The influence of maternal, fetal and child nutrition on the development of chronic disease in later life; www.sacn.gov.uk/; 2011.

8 de Onis M, Blossner M, Borghi E. Global prevalence and trends of overweight and obesity among preschool children. Am J Clin Nutr 2010;92(5):1257-64. 
9 Harrington DM, Belton S, Coppinger T et al. Results from Ireland's 2014 Report Card on Physical Activity in Children and Youth. J Phys Act Health 2014;11(Suppl 1):S63-8.

10 Barnett LM, Salmon J, Hesketh KD. More active pre-school children have better motor competence at school starting age: an observational cohort study. BMC Public Health 2016;16(1):1068.

11 Flynn MA, McNeil DA, Maloff B et al. Reducing obesity and related chronic disease risk in children and youth: a synthesis of evidence with 'best practice' recommendations. Obes Rev 2006;7(Suppl 1): 7-66.

12 Wolfenden L, Jones J, Williams CM et al. Strategies to improve the implementation of healthy eating, physical activity and obesity prevention policies, practices or programmes within childcare services. Cocbrane Database Syst Rev 2016;10:Cd011779.

13 Gupta RS, Shuman S, Taveras EM et al. Opportunities for health promotion education in child care. Pediatrics 2005;116:e499-505.

14 Hodges EA, Smith C, Tidwell S et al. Promoting physical activity in preschoolers to prevent obesity: a review of the literature. $J$ Pediatr Nurs 2013;28(1):3-19.

15 Kaphingst KM, Story M. Child care as an untapped setting for obesity prevention: state child care licensing regulations related to nutrition, physical activity, and media use for preschool-aged children in the United States. Prev Chronic Dis 2009;6:A11.

16 Parker M, Lloyd-Williams F, Weston G et al. Nursery nutrition in Liverpool: an exploration of practice and nutritional analysis of food provided. Public Health Nutr 2011;14:1867-75.

17 Gubbels JS, Kremers SP, Stafleu A et al. Child-care environment and dietary intake of 2- and 3-year-old children. J Hum Nutr Diet 2010;23:97-101.

18 Erinosho TO, Ball SC, Hanson PP et al. Assessing foods offered to children at child-care centers using the Healthy Eating Index-2005. J Acad Nutr Diet. 2013;113(8):1084-9.

19 Foster JS, Contreras D, Gold A et al. Evaluation of nutrition and physical activity policies and practices in child care centers within rural communities. ; Child Obes 2015;11(5):506-12.

20 Border Counties Childhood Network; What is Smart Start?; www. bccn.ie/dynamicpages.php?id=56; 2014.

21 Johnston Molloy C; The Healthy Incentive for Pre-schools (HIP) Project: The Development, Validation, Evaluation and Implementation of an Healthy Incentive Scheme in the Irish Full Day Care Pre-school Setting; arrow.dit.ie/sciendoc; 2013.

22 De Craemer M, De Decker E, Verloigne M et al. The effect of a kindergarten-based, family-involved intervention on objectively measured physical activity in Belgian preschool boys and girls of high and low SES: the ToyBox-study. Int J Behav Nutr Phys Act 2014;11(1):38.

23 Lanigan J, Collins S, Birbara T et al. The TrimTots programme for prevention and treatment of obesity in preschool children: evidence from two randomised controlled trials. Lancet 2013;382:S58.

24 Davis SM, Sanders SG, FitzGerald CA et al. CHILE: an evidencebased preschool intervention for obesity prevention in Head Start. J Sch Health 2013;83(3):223-9.

25 Bell LK, Hendrie GA, Hartley J et al. Impact of a nutrition award scheme on the food and nutrient intakes of 2- to 4-year-olds attending long day care. Public Health Nutr 2015;18(14):2634-42.
26 Willis T, Roberts K, Berry $\mathrm{T}$ et al. The impact of HENRY on parenting and family lifestyle: a national service evaluation of a preschool obesity prevention programme. Public Health 2016;136:101-8.

27 Johnston Molloy C, Kearney J, Hayes N et al. Pre-school manager training: a cost-effective tool to promote nutrition- and healthrelated practice improvements in the Irish full-day-care pre-school setting. Public Health Nutr 2013;18(9):1554-64.

28 Scheirer MA. Linking sustainability research to intervention types. Am J Public Health 2013;103(4):e73-80.

29 Virani T, Lemieux-Charles L, Davis DA et al. Sustaining change: once evidence-based practices are transferred, what then? Healthc $\mathcal{Q}$ 2009;12(1):89-96, 2.

30 Chang DI, Gertel-Rosenberg A, Snyder K. Accelerating efforts to prevent childhood obesity: spreading, scaling, and sustaining healthy eating and physical activity. Health Aff (Millwood) 2014;33:2207-13.

31 Johnston Molloy C, Corish C, Kearney J et al. Developing a nutrition assessment tool for Irish pre-schools. Nutr Food Sci 2011;41(1): 44-53.

32 Safefood; What is a Serving Size? A Guide for Pre-schools; www. safefood.eu; 2013.

33 Langford R, Bonell CP, Jones HE et al. The WHO Health Promoting School framework for improving the health and wellbeing of students and their academic achievement. Cocbrane Database Syst Rev 2014;4:Cd008958.

34 Altman DG. Challenges in sustaining public health interventions. Health Educ Behav 2009;36(1):24-8. discussion 9-30.

35 Jennings A, McEvoy S, Corish C. Nutritional practices in full-daycare pre-schools. J Hum Nutr Diet 2011;24(3):245-59.

36 Hayes N, Bradley S; Early Childhood Education and Care in Ireland: Getting it Right for Children; CSER Early Childhood Care and Education Policy Seminar Series; Seminar 2; DIT Mountjoy Square; 2008.

37 Golley RK, Bell L, Matwiejczyk L et al. South Australian Long Day Care Centres engaged with a nutrition incentive award scheme show consistency with mealtime practice guidelines. Nutr Diet 2012;69(2): 130-6.

38 Boller K, Paulsell D, Del Grosso P et al. Impacts of a child care quality rating and improvement system on child care quality. Early Child Res Q 2015;30:306-15.

39 Yazejian N, Iruka IU. Associations among tiered quality rating and improvement system supports and quality improvement. Early Child Res Q 2014;30:255-65.

40 Goffin SG, Barnett WS. Assessing QRIS as a change agent. Early Child Res Q 2015;30:179-82.

41 Greaney ML, Hardwick CK, Spadano-Gasbarro JL et al. Implementing a multicomponent school-based obesity prevention intervention: a qualitative study. J Nutr Educ Behav 2014;46(6):576-82.

42 Friend S, Flattum CF, Simpson D et al. The researchers have left the building: what contributes to sustaining school-based interventions following the conclusion of formal research support. $J S_{c h}$ Health 2014;84(5):326-33.

43 Han SS, Weiss B. Sustainability of teacher implementation of school-based mental health programs. J Abnorm Child Psychol 2005; 33(6):665-79. 
44 Siraj I, Hallet E. Effective and Caring Leadership in the Early Years. UCL Institute of Education, University College London, UK; London: Sage, 2013.

45 Håkansson J. Organising and leading systematic quality work in the preschool-preschool managers' perspectives. Sch Leadersh Manage 2016;36(3):292-310.

46 Kirshbaum M. Translation to practice: a randomised, controlled study of an evidence-based booklet for breast-care nurses in the United Kingdom. Worldviews Evid Based Nurs 2008; 5:60-74.

47 Oxman AD, Thomson MA, Davis DA et al. No magic bullets: a systematic review of 102 trials of interventions to improve professional practice. CMAJ 1995;153(10):1423-31.
48 Adler PA. Membership roles in field research. University of Denver, USA; California: Sage, 1987.

49 Gittelsohn J, Shankar AV, Pokhrel RP et al. Accuracy of estimating food intake by observation. J Am Diet Assoc 1994;94:1273-7.

50 Baglio ML, Baxter SD, Guinn CH et al. Assessment of interobserver reliability in nutrition studies that use direct observation of school meals. J Am Diet Assoc 2004;104:1385-92.

51 Richter SL, Vandervet LM, Macaskill LA et al. Accuracy and reliability of direct observations of home-packed lunches in elementary schools by trained nutrition students. J Acad Nutr Diet 2012;112(10):1603-7.

52 Ahern SM, Caton SJ, Blundell P et al. The root of the problem: increasing root vegetable intake in preschool children by repeated exposure and flavour flavour learning. Appetite 2014;80:154-60. 